\title{
Activities and Kinetic Properties of Lumbar Cerebrospinal Fluid Cholinesterases in Relation to Clinical Diagnosis, Severity, and Progression of Alzheimer's Disease
}

\author{
F. Jacob Huff, Clara T. Reiter and Jack Protetch
}

\begin{abstract}
Acetylcholinesterase (AChE) and butyrylcholinesterase (BChE) activities of lumbar cerebrospinal fluid (CSF) have been measured in seventeen patients with a clinical diagnosis of probable Alzheimer's disease (Prob AD), possible Alzheimer's disease (Poss AD), or dementia of non-Alzheimer aetiology (Non-AD). The three diagnostic groups did not differ with regard to the $\mathrm{K}_{\mathrm{m}}$ or saturation kinetic properties of AChE and BChE. The CSF AChE activity was significantly higher in Prob AD than in Non-AD patients. The groups did not differ significantly in $B C h E$ activity. The ratio of $A C h E$ to $B C h E$ activity was significantly higher in both the Prob $A D$ and Poss AD groups than in the Non-AD group, and the ranges of values in the Prob AD and Non-AD groups did not overlap. Among patients in the Prob AD group, severity of dementia was correlated with both AChE activity and the AChE/BChE ratio, and progression of dementia over time was also correlated with $\mathrm{AChE} / \mathrm{BChE}$.

The $\mathrm{AChE} / \mathrm{BChE}$ ratio correlated more strongly than $\mathrm{AChE}$ with severity and progression of dementia in Prob AD patients, and also better distinguished them from Non-AD patients, suggesting that $\mathrm{AChE} / \mathrm{BChE}$ may be the more useful marker for diagnosis of $\mathrm{AD}$. It is not clear from the results whether $\mathrm{AChE} / \mathrm{BChE}$ is useful for diagnosis of the complex dementia cases in the Poss AD group.

RÉSUMÉ: Activité et propriétés cinétiques des cholinestérases du liquide céphalo-rachidien lombaire en relation avec le diagnostic clinique, la sévérité et la progression de la maladie d'Alzheimer L'activité de l'acétylcholinestérase $(\mathrm{AChE})$ et de la butyrylcholinestérase (BChE) du liquide céphalo-rachidien (LCR) lombaire ont été mesurées chez dix-sept patients avec un diagnostic de maladie d'Alzheimer probable (Prob MA), maladie d'Alzheimer possible (Poss MA), ou démence d'étiologie autre (Non-MA). Les trois groupes de patients ne différaient pas quant au $\mathrm{K}_{\mathrm{m}}$ ou auz propriétés cinétiques de saturation de l'AChE et de la BChE. L'activité de l'AChE dans le LCR était significativement plus élevée chez les Prob MA que chez les Non-MA. Les deux groupes ne différaient pas significativement quant à l'activité de la BChE. Le rapport entre l'activité $\mathrm{AChE}$ et l'activité $\mathrm{BChE}$ était significativement plus élevé dans les groupes Prob MA et Poss MA que dans le groupe Non-MA, et l'écart des valeurs dans les groupes Prob MA et Non-MA ne se chevauchaient pas. Parmi les patients du groupe Prob MA, la sévérité de la démence était en corrélation avec l'activité de l'AChE et le rapport $\mathrm{AChE} / \mathrm{BChE}$, et la progression de la démence dans le temps était égale-

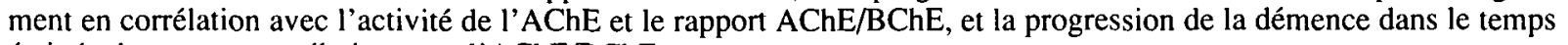
était également en corrélation avec l'AChE/BChE.

La corrélation entre le rapport $\mathrm{AChE} / \mathrm{BChE}$ et la sévérité et la progression de la démence chez les patients Prob MA était plus forte que celle de l'AChE et les distinguait mieux des patients Non-MA, suggérant que l'AChE/BChE peut être le marqueur le plus utile pour le diagnostic de la MA. Ces résultats ne nous permettent pas de déterminer si l'AChE/BChE est utile dans le diagnostic des cas complexes de deménce du groupe Poss MA.
\end{abstract}

Can. J. Neurol. Sci. 1989; 16: 406-410

A deficiency of acetylcholinesterase (AChE) has been observed in brain tissue from patients with Alzheimer's disease (AD), and association of this deficit with a deficiency of choline acetyltransferase ${ }^{1}$ suggests that it results from a loss of cholinergic neurons in the brain. ${ }^{2,3}$ An increase in nonspecific cholinesterase activity attributable to butyrylcholinesterase (BChE) has also been found in AD brain, and the decreased $\mathrm{AChE}$ and increased $\mathrm{BChE}$ in $\mathrm{AD}$ are correlated both with the number of senile plaques in the brain and the clinical severity of dementia. ${ }^{1,4}$ Because both $\mathrm{AChE}$ and $\mathrm{BChE}$ activities are mea-

From the Departments of Neurology and Psychiatry, Alzheimer's Disease Research Center, Western Psychiatric Institute and Clinic, University of Pittsburgh School of Medicine

Received March 9, 1989. Accepted May 22, 1989

Reprint requests to: F. Jacob Huff, M.D., Neuroscience Research Group, Hoechst-Roussel Pharmaceuticals, Routes 202-206, Building M-338, Somerville, N.J. USA 08876 
surable in the cerebrospinal fluid (CSF), numerous studies have attempted to establish whether or not the brain abnormalities of these enzymes in AD are detectable in the CSF. Studies comparing $\mathrm{AD}$ patients to nondemented control cases have produced conflicting results: AChE in lumbar CSF and AD cases has been reported to be decreased in some studies ${ }^{5-10}$ but unchanged in others $\mathrm{H}^{1-18}$ whereas $\mathrm{BChE}$ activity has been variously reported to be decreased ${ }^{10,15,18}$ or unchanged. $9,14,16,17$ Because the brain abnormalities of $\mathrm{AChE}$ and $\mathrm{BChE}$ in $\mathrm{AD}$ are in opposite directions from the norm, the AChE/BChE ratio in CSF has been studied, again with conflicting results. $6,9,10,14,15,17,18$

The variable results in these studies may be due to methodological differences among them. Many investigators did not inhibit BChE when assaying AChE activity, and thus measured total cholinesterase activity rather than specific $\mathrm{AChE}$ activity. Most studies have relied on clinical criteria for diagnosis of $A D$, and inclusion of patients with mixed dementia in the $A D$ group of some studies may have affected the results, in view of the evidence that patients with Non-AD dementia have different patterns of CSF cholinesterase abnormalities than patients with AD. ${ }^{16,18}$ In a recent study of lumbar CSF in AD cases diagnosed on the basis of cortical biopsy, 18 BChE activity was decreased and the $\mathrm{AChE} / \mathrm{BChE}$ ratio was increased in $\mathrm{AD}$ compared to non-demented control cases. In the same study, the $\mathrm{AChE} / \mathrm{BChE}$ ratio was increased in ventricular CSF from $A D$ cases diagnosed by autopsy. These results provide strong evidence that the cholinesterase abnormalities in AD brain are reflected in CSF, and suggest that the $\mathrm{AChE} / \mathrm{BChE}$ ratio in lumbar CSF may be useful in the diagnosis of $A D$.

The present investigation incorporated a number of methodological improvements over previous clinical studies. AChE was measured in the presence of an inhibitor of $\mathrm{BChE}$. Moreover, the quantitative measures of $\mathrm{AChE}$ and $\mathrm{BChE}$ activity used in the present study were extrapolated estimates of $\mathrm{V}_{\max }$ derived from assays at five subsaturation substrate concentrations. Under conditions of substrate saturation, $\mathrm{AChE}$ undergoes inhibition, whereas $\mathrm{BChE}$ activity is enhanced due to cooperative kinetics, ${ }^{19}$ resulting in a lower estimation of the $\mathrm{AChE}$ activity and a higher estimation of the BChE activity in a specimen. The extrapolated $\mathrm{V}_{\text {max }}$ measures used in the present study thus enhance the precision in determining the $\mathrm{AChE} / \mathrm{BChE}$ ratio, and also allow determination of the degree of substrate inhibition of $\mathrm{AChE}$. Previous studies have indicated that AChE from cerebral cortex and ventricular $\mathrm{CSF}^{18}$ of patients with $\mathrm{AD}$ does not exhibit the normal substrate inhibition.

Another methodological issue addressed in the present study was the diagnostic classification of patients. Patients were diagnosed according to the NINCDS-ADRDA criteria, which were developed by a Task Force convened under the auspices of the National Institutes of Health of the United States. ${ }^{20}$ These criteria distinguish patients with "probable AD", in whom all other identifiable causes of dementia have been excluded, from patients with "possible AD", in whom another condition that may cause dementia is present but is not considered to be sufficient alone to account for the patient's dementia symptoms. By distinguishing patients in these diagnostic categories, the present investigation permitted analyses of the degree to which the relationship of CSF cholinesterases to the severity and rate of progression of dementia may be specific to $\mathrm{AD}$, and of possible differences in the sensitivity of CSF cholinesterases for diagnosing
AD depending on whether the latter is the sole aetiology for dementia or is present in conjunction with other aetiologies. The comparison group for evaluating the usefulness of CSF cholinesterases in the diagnosis of $\mathrm{AD}$ was a group of patients with dementia that was entirely attributable to an aetiology other than AD. In an effort to enhance the accuracy of the clinical diagnoses, as well as to measure the progression of dementia, patients in the present investigation were re-examined longitudinally after their initial examination.

\section{METHODS}

\section{Patients}

All patients or a relative responsible for them gave informed consent prior to their participation in the investigation.

Probable $A D$ (Prob AD) was diagnosed in six women and one man based on confirmation of dementia by neurological history and examination, and exclusion of aetiologies other than AD that could cause or contribute to the dementia. All patients had a CT brain scan, electroencephalogram, blood tests of thyroid, hepatic and renal function, vitamin $B_{12}$ and folic acid levels, and a serologic test for treponemal disease. A Hachinski Ischemia Scale ${ }^{21}$ score of five or more was exclusionary. The Dementia Rating Scale (DRS) of Mattis ${ }^{22,23}$ was administered in all cases in order to confirm the diagnosis of dementia and to quantitate its severity. Table 1 describes the ages and DRS scores of patients in the Prob AD and other diagnostic groups.

Possible AD (Poss AD) was diagnosed in three women and four men on the basis of the same diagnostic evaluation used for Prob AD. Patients with Poss AD had a neurological history and examination compatible with $A D$, but either had atypical features in their clinical presentation, or had another disorder that could contribute to the aetiology of their dementia. ${ }^{20}$ Two patients had Poss AD with atypical features: one had prominent aphasic symptoms and the other had prominent visuospatial impairment, these being the first symptoms of dementia described historically and also the most prominent symptoms at the time of their respective examinations. Three patients were diagnosed as Poss AD with cerebrovascular disease, either because the Hachinski Scale score was 5 or greater, or because a single cerebrovascular accident was documented on neurological examination or CT brain scan. One patient had a diagnosis of Poss AD with major depression. Another patient had a history of alcohol abuse with persistent dementia after six months of abstinence.

Table 1: Age and Dementia Rating Scale Scores. ${ }^{1}$

\begin{tabular}{cccc}
\hline \hline Group & $\begin{array}{c}\text { Age } \\
\text { (Years) }\end{array}$ & $\begin{array}{c}\text { Baseline } \\
\text { DRS }\end{array}$ & $\begin{array}{c}\text { Change in DRS } \\
\text { (points per month) }\end{array}$ \\
\hline $\begin{array}{c}\text { Prob AD } \\
\text { (n=6) }\end{array}$ & $72.3(6.6)$ & $105(20)$ & $1.6(1.2)$ \\
Poss AD & 694 to 84$)$ & $(78$ to 133$)$ & $(0.2$ to 3.3$)$ \\
$(\mathrm{n}-7)^{2}$ & $(55$ to 82$)$ & $89(58)$ & $1.9(4.0)$ \\
Non-AD & $61.2(22)$ & $123(15)$ & $(-1.0$ to 8.8$)$ \\
(n=4) & $(39$ to 88$)$ & $(107$ to 142$)$ & $0.3(0.9)$ \\
\end{tabular}

1 Table entries indicate the group mean followed by (standard deviation)/(range).

${ }^{2} \mathrm{n}=5$ for change in DRS: a second DRS score was not obtained in 2 cases. 
Non-AD Dementia was diagnosed in one woman and three men. Two patients had multiple infarct dementia (MID) diagnosed on the basis of multiple cerebral infarctions documented by clinical examination and CT brain scan. Another had a mild dementia, dysarthria and ataxia associated with a chromosome 4;6 translocation. ${ }^{24}$ The fourth patient had a slowly progressive dementia syndrome without other neurological signs, but had multiple relatives with either amyotrophic lateral sclerosis or Parkinson's disease; a temporal lobe biopsy showed only minimal astrocytic gliosis.

\section{Procedure}

Lumbar Puncture Patients were not given psychoactive drugs for two weeks prior to the lumbar puncture, which in all cases was performed between 9 and $10 \mathrm{AM}$ after a night of recumbency monitored by nursing staff. All CSF samples used for the study were free of blood, and one patient with Prob AD (not described in Table 1) was excluded because of traumatic blood contamination of the CSF. The 3rd through 18th milliliter $(\mathrm{ml})$ of CSF were collected in 4 sequential $4 \mathrm{ml}$ samples, from which equal volume aliquots were combined to create the final samples used for the cholinesterase measurements described below.

Neuropsychological Testing Baseline neuropsychological testing was performed within 3 days of the lumbar puncture, and was repeated after an interval of 8 to 23 months. Two patients, both diagnosed as Poss $\mathrm{AD}$ with atypical features, did not have follow-up neuropsychological testing. The patient with prominent aphasia had progressed to the point of being untestable; his baseline DRS was 3 , and repeat testing would thus have been of limited value for measuring progression. The other patient declined to have repeat testing.

CSF cholinesterase measurements Biochemical analyses were performed without knowledge of the diagnosis. CSF AChE was measured using a single-vial radiometric method with ${ }^{3} \mathrm{H}$-acetyl-labeled acetylcholine as the substrate. ${ }^{25}$ Assays were performed at $30^{\circ} \mathrm{C}, \mathrm{pH} 8.0$, in the presence of $150 \mathrm{mM}$ sodium and $10^{-5.33} \mathrm{M}$ ethopropazine. In preliminary studies, this concentration of ethopropazine was found to inhibit 90 to $95 \%$ of BChE activity and only 5 to $10 \%$ of AChE activity. 26 The $\mathrm{K}_{\mathrm{m}}$ of each CSF sample was estimated as the slope of the EadieHofstee plot for five substrate levels $(0.3$ to $500 \mathrm{uM})$, each run in triplicate, and $V_{\max }$ was determined by extrapolation from the same slope. AChE activity in nanomoles of substrate hydrolyzed per minute per $\mathrm{ml}$ of CSF was calculated from $\mathrm{V}_{\max }$. Using this method, the coefficients of variation for repeated assays of the same specimen on difference days were .022 for $\mathrm{Km}$ and .029 for AChE activity. CSF BChE was measured by a similar assay using ${ }^{3} \mathrm{H}$-butyryl-labeled butyrylcholine as the substrate, in five concentrations ranging from 0.01 to $80 \mathrm{uM}$. The coefficients of variation for this assay were .069 for $\mathrm{Km}$ and .020 for BChE activity. Enzyme specific activities were calculated on basis of CSF protein determinations using the BioRad method. Saturation kinetics were measured using higher substrate levels in the AChE and BChE assays. For AChE, substrate inhibition was measured by determining the ratio of enzyme activities at substrate concentrations of $10 \mathrm{mM}$ and $1 \mathrm{mM}$ of $\mathrm{ACh}$. For $\mathrm{BChE}$, the ratio of activities at $2 \mathrm{mM}$ and $0.08 \mathrm{mM}$ of $\mathrm{BCh}$ was used to measure the increase in enzyme activity due to cooperative kinetics at the higher substrate concentration.
Statistical Analysis Results were analyzed by Student's $t$ test and by the Spearman rank correlation $\left(r_{\mathrm{S}}\right)$ test.

\section{RESUlTS}

Table 1 presents the baseline DRS scores and change in scores between the baseline and follow-up testing for patients in the Prob AD, Poss AD and Non-AD groups. Means for the Prob $A D$ and Poss $A D$ groups did not differ from one another or from the Non-AD group mean for either measure.

Table 2 presents the CSF activities of AChE and BChE and their ratio. Enzyme activities were evaluated both in units of nanomoles ( $\mathrm{nmol}$ ) of substrate hydrolyzed per minute (min) per milliliter ( $\mathrm{ml}$ ) of CSF and in specific activity units ( $\mathrm{nmol} / \mathrm{min} / \mathrm{milligram}$ of protein). The pattern of results was the same using either unit of measure, and the data are therefore presented only for the volumetric $(\mathrm{nmol} / \mathrm{min} / \mathrm{ml})$ units. Means for the Prob AD and Poss AD groups did not differ for any measure. The mean AChE activity was significantly greater in the Prob $\mathrm{AD}$ than in the Non-AD group, although the range of values in the two groups overlapped. The mean $\mathrm{AChE} / \mathrm{BChE}$ ratio was significantly greater in both the Prob AD and Poss AD groups than in the Non-AD group, and the ranges of values for the Prob AD and Non-AD groups were distinct.

The AChE/BChE values of 3 Poss AD patients overlapped the Prob AD group range: two of these were the Poss AD patients with atypical features, and the third was a case of Poss AD with associated CVD. The remaining Poss AD patients had $\mathrm{AChE} / \mathrm{BChE}$ values that overlapped the Non-AD range. Two of these were cases of Poss AD with CVD; the others represented Poss AD with associated depression and alcoholism, respectively. The case with alcoholism had an $\mathrm{AChE} / \mathrm{BChE}$ value of 3.3 and a DRS change score of -1.0 , indicating improvement during a year of abstinence from alcohol, and suggesting that alcoholism and not AD was the aetiology of dementia. The followup examinations in the remaining Poss AD cases did not establish the aetiology of dementia, and it is not clear in these cases whether the ratio of $\mathrm{AChE}$ to $\mathrm{BChE}$ differentiates those with $\mathrm{AD}$ from those who do not have AD.

Among patients in the Prob AD group, baseline DRS scores were strongly correlated with both CSF AChE $\left(r_{\mathrm{S}}=.77, p<.05\right)$ and the AChE/BChE ratio $\left(r_{\mathrm{S}}=.94, p<.001\right)$. Changes in DRS scores over time were also highly correlated with the AChE/BChE ratio $\left(r_{\mathrm{s}}=.77, p<.05\right)$. When patients with Prob $\mathrm{AD}$ and Poss AD were examined as a pooled group, the correla-

Table 2: CSF Cholinesterase Activities ${ }^{1}$

\begin{tabular}{cccc}
\hline & \multicolumn{2}{c}{ Activity $(\mathbf{n m o l} / \mathbf{m i n} / \mathbf{m l})$} & \\
\cline { 2 - 3 } Group & AChE & BChE & AChE/BChE Ratio \\
\hline Prob AD & $29.6^{*}(7.6)$ & $7.0(1.6)$ & $4.3^{* *}(0.6)$ \\
(n=6) & $(23$ to 44$)$ & $(5.6$ to 10$)$ & $(3.8$ to 5.3$)$ \\
Poss AD & $23.8(4.8)$ & $6.6(1.0)$ & $3.6^{*}(0.3)$ \\
(n-7) & $(17$ to 33$)$ & $(5.2$ to 8.3$)$ & $(3.3$ to 4.0$)$ \\
Non-AD & $17.1(9.4)$ & $5.6(2.8)$ & $3.0(0.6)$ \\
(n=4) & $(5.5$ to 28$)$ & $(2.4$ to 9.0$)$ & $(2.3$ to 3.7$)$ \\
\hline
\end{tabular}

1 The table entries indicate group mean (standard deviation)/(range). Means that differed from the Non-AD mean by $t-$ test: ${ }^{*} p<.05$, $* * p<.01$. 
tion between baseline DRS and CSF AChE remained strong $\left(r_{\mathrm{S}}=.50, p<.05\right)$, although it was lower than that in the Prob AD group alone, and the significance of the other correlations fell below an alpha level of .05 . When all cases were examined, pooling the Non-AD group with the others, none of the correlations were significant statistically.

Table 3 presents the $K_{m}$ values and measures of saturation kinetics for $\mathrm{AChE}$ and $\mathrm{BChE}$. There were no significant differences among the diagnostic groups for any of these measures. The trend toward less substrate inhibition in the Non-AD group is attributable to one subject in that group who did not manifest substrate inhibition.

\section{Discussion}

In the Introduction we indicated that previous studies of CSF cholinesterases comparing AD cases with non-demented control cases have produced equivocal results. The present investigation examined a different but clinically important diagnostic question: are CSF cholinesterase measurements useful for differentiating $A D$ cases from cases of Non-AD dementia? Our findings of increased $\mathrm{AChE}$ and $\mathrm{AChE} / \mathrm{BChE}$ ratio in $\mathrm{AD}$ compared to Non-AD cases correspond to the results of Appleyard et al ${ }^{18}$ for lumbar CSF from patients diagnosed by cortical biopsy as well as by clinical criteria. Other studies have reported overlap in the values of $A D$ and Non-AD dementia cases for $A C h E^{7,13,16,27}$ and for $B C h E, 16,27$ but none of those studies examined the $\mathrm{AChE} / \mathrm{BChE}$ ratio.

The original reason ${ }^{6}$ for examining the $\mathrm{AChE} / \mathrm{BChE}$ ratio was that the brain abnormalities of $\mathrm{AChE}$ and $\mathrm{BChE}$ were reported to differ in opposite directions from the norm, ${ }^{4}$ and on the assumption that these abnormalities would be reflected in CSF it was expected that the CSF AChE/BChE ratio would enhance the discrimination between $A D$ and non-AD cases beyond the discrimination achieved using either enzyme alone. There is no direct evidence that $\mathrm{AChE}$ and $\mathrm{BChE}$ are metabolically related, but the observation in the present investigation that the $\mathrm{AChE} / \mathrm{BChE}$ ratio correlated more strongly than did $\mathrm{AChE}$ alone with severity and progression of dementia supports the hypothesis that abnormalities in both $\mathrm{AChE}$ and $\mathrm{BChE}$ are associated with the pathophysiologic process in $\mathrm{AD}$.

\begin{tabular}{cccccc}
\hline Table 3: Kinetic Properties of CSF Cholinesterases \\
\hline \hline & \multicolumn{2}{c}{$\mathbf{K}_{\mathbf{m}}(\mu \mathrm{mol} / \mathbf{L})$} & & \multicolumn{2}{c}{ Saturation Kinetics } \\
\cline { 2 - 3 } \cline { 5 - 6 } Group & $\mathbf{A C h E}$ & $\mathbf{B C h E}$ & & $\mathbf{A C h E ^ { 2 }}$ & $\mathbf{B C h E}^{3}$ \\
\hline Prob AD & $130(5.3)$ & $18.9(1.3)$ & & $0.67(0.05)$ & $1.48(0.04)$ \\
$(\mathrm{n}=6)$ & $(124$ to 140$)$ & $(17.4$ to 20.7$)$ & $(0.59$ to 0.73$)$ & $(1.4$ to 1.5$)$ \\
Poss AD & $132(6.8)$ & $19.7(1.2)$ & $0.71(0.06)$ & $1.43(0.11)$ \\
$(\mathrm{n}-7)$ & $(122$ to 140$)$ & $(18.2$ to 21.3$)$ & $(0.61$ to 0.76$)$ & $(1.3$ to 1.6$)$ \\
Non-AD & $129(4.9)$ & $18.1(1.6)$ & $0.84(0.20)$ & $1.50(0.14)$ \\
$(n=4)$ & $(123$ to 135$)$ & $(17.0$ to 20.4$)$ & $(0.65$ to 1.12$)$ & $(1.4$ to 1.7$)$ \\
\hline
\end{tabular}

${ }^{1}$ The table entries indicate group mean (standard deviation)/(range). The group means did not differ at $p<.05$ by $t$ - test for any of the variables.

${ }^{2}$ Values represent the ratio of $\mathrm{AChE}$ activities at substrate concentrations of $10 \mathrm{mM}$ and $1 \mathrm{mM}$ of $\mathrm{ACh}$.

${ }^{3}$ Values represent the ratio of $\mathrm{BChE}$ activities at substrate concentrations of $2 \mathrm{mM}$ and $.08 \mathrm{mM}$ of $\mathrm{BCh}$.
These observations suggest that the $\mathrm{AChE} / \mathrm{BChE}$ ratio in lumbar CSF may be more useful for diagnosis of AD than measurement of either $\mathrm{AChE}$ or $\mathrm{BChE}$ alone. Although the ratio measure distinguished Prob AD from Non-AD dementia cases, it is not clear from the results whether it is useful for diagnosis of the complex dementia cases in the Poss AD group. Resolution of that question awaits histopathological diagnosis by postmortem autopsy in those cases.

The decrease in lumbar CSF BChE activity and increase in $\mathrm{AChE} / \mathrm{BChE}$ ratio in $\mathrm{AD}$ cases compared to non-demented control cases that were observed in two previous investigations 15,18 were not found in two other large case series that have recently been published.9,17 Those negative results sound a note of caution regarding the prospect of using the $\mathrm{CSF} A \mathrm{AChE} / \mathrm{BChE}$ ratio for the diagnosis of $\mathrm{AD}$. However, the clinical diagnosis of $\mathrm{AD}$ remains vulnerable to error, and it is possible that misclassification of some cases in those studies altered the discrimination between the $A D$ and control groups using the $A C h E / B C h E$ ratio. Another factor that may have altered the discrimination is the fact that in one of those studies ${ }^{9}$ the activities of $\mathrm{BChE}$ and to a lesser degree $\mathrm{AChE}$ were measured using high substrate concentrations. (The other report did not specify the substrate concentrations that were used.) As the present investigation has demonstrated, at high substrate concentrations the measured activity of $\mathrm{AChE}$ decreases whereas that of $\mathrm{BChE}$ increases. Both of these effects diminish the $\mathrm{AChE} / \mathrm{BChE}$ ratio, and may have the consequence of reducing or reversing the direction of differences in that ratio among cases or between diagnostic groups.

No differences in the saturation kinetic properties of $\mathrm{K}_{\mathrm{m}}$ values for $\mathrm{AChE}$ or $\mathrm{BChE}$ in lumbar $\mathrm{CSF}$ were found in the present study. Appleyard et all8 found that AChE in ventricular CSF from patients with AD did not exhibit substrate inhibition, which is consistent with previous observations by Perry and Perry 28 on brain AChE in AD. As in the present investigation, $\mathrm{AChE}$ in lumbar CSF from AD cases examined by Appleyard et al did exhibit substrate inhibition. These observations suggest that some of the AChE in lumbar CSF originates from sources other that the brain. Lal et al ${ }^{13}$ found no gradient in AChE activity levels from sequential samples of lumbar CSF, suggesting that CSF AChE originates from the spinal cord as well as the brain. We also found no gradient in the activities of $\mathrm{AChE}$ or $\mathrm{BChE}$ in sequential $4 \mathrm{ml}$ samples of CSF examined in 7 of our cases (data not shown). The apparently diffuse origin of cholinesterases in lumbar CSF may diminish their sensitivity as indicators of the brain cholinesterase abnormalities in AD. However, even if some lumbar CSF cholinesterases originate from sources other than the brain, changes in brain activities may result in altered activities in lumbar CSF.

Strong correlations between lumbar CSF cholinesterase activities and dementia severity in Prob AD cases have been found in previous studies 15,18 based on different case series and using different neuropsychological and neurochemical methods. Others, however, have failed to find such strong correlations. 7,13,16,17 These discrepancies may be attributable to differences in the sensitivities of the severity measures that were used, or to differences in the subject populations studied. In the present investigation, severity was measured using the Mattis Dementia Rating Scale, which has a range of 144 points along which scores may be distributed, thereby enhancing sensitivity to dif- 
ferences in severity between cases beyond what is detectable by the brief scales used in other studies. The strong correlations between severity and CSF cholinesterase measures in the Prob $A D$ group were not observed when Prob $A D$ and Poss AD cases were pooled together. The lower correlations found in other studies may have resulted from inclusion of some cases whose dementia results from a combination of $\mathrm{AD}$ and other aetiologies for dementia. If the relationship between CSF cholinesterases and dementia is unique to $A D$, inclusion of cases with mixed aetiologies of dementia would have the effect of reducing the ability to detect the correlation.

Although CSF cholinesterases have been measured longitudinally, 9,17 no previous study has examined the longitudinal progression of dementia in relation to CSF cholinesterase activities. The observation in the present study that the CSF AChE/BChE ratio correlates with rate of dementia progression in cases with Prob $A D$ raises the possibility that this measure may be useful in clinical prognosis. The fact that the correlation is significant only for the Prob AD group again suggests the specificity of the relationship to $A D$ in contrast to other aetiologies of dementia.

\section{ACKNOWLEDGEMENTS}

We are grateful to the staff of the Presbyterian-University Hospital Clinical Research Unit and the University of Pittsburgh Alzheimer's Disease Research Center for patient care during the study, to Lisa Mack for administering neuropsychological tests, and to Debra Johnson for preparing the manuscript. This work was supported by United States National Institutes of Health Grants AG05133, MH30915, and RR00056.

\section{REFERENCES}

I. Perry EK, Tomlinson BE, Blessed G, et al. Correlation of cholinergic abnormalities with senile plaques and mental test scores in senile dementia. Brit Med J 1987; 2: 1457-1459.

2. Bowen DM, Smith CB, White P, et al. Neurotransmitter-related enzymes and indices of hypoxia in senile dementia and other abiotrophies. Brain 1976; 99: 459-496.

3. Rossor MN, Garrett NJ, Johnson AL, et al. A post-mortem study of the cholinergic and GABA systems in senile dementia. Brain 1982; 105: 313-330.

4. Perry EK, Perry RH, Blessed G, et al. Changes in brain cholinesterases in senile dementia of Alzheimer type. Neuropathol Appl Neurobiol 1978; 4: 273-277.

5. Soininen HS, Jolkkonen JT, Reinikainen KJ, et al. Reduced cholinesterase activity and somatostatin-like immunoreactivity in the cerebrospinal fluid of patients with dementia of the Alzheimer type. J Neurol Sci 1984; 63: 167-172.

6. Arendt T, Bigl V, Walther F, et al. Decreased ratio of CSF acetylcholinesterase to butyrylcholinesterase activity in Alzheimer's disease. Lancet 1984; i: 173.

7. Tune L, Gucker S, Folstein M, et al. Cerebrospinal fluid acetylcholinesterase activity in senile dementia of the Alzheimer type. Ann Neurol 1985; 17: 46-48.

8. Nakano S, Kato T, Nakamura S, et al. Acetylcholinesterase activity in cerebrospinal fluid of patients with Alzheimer's disease and senile dementia. J Neurol Sci 1986; 75: 213-223.

9. Atack JR, May C, Kaye JA, et al. Cerebrospinal fluid cholinesterases in aging and in dementia of the Alzheimer type. Ann Neurol 1988; $23: 161-167$.
10. Sirvio J, Kutvonen R, Soininen $\mathrm{H}$, et al. Cholinesterases in the cerebrospinal fluid, plasma, and erythrocytes of patients with Alzheimer's disease. J Neural Transm 1989; 75: 119-127.

11. Davies P. Neurotransmitter-related enzymes in senile dementia of the Alzheimer type. Brain Res, Amsterdam 1979; 171: 319-327.

12. Deutsch SI, Mohs RC, Levy MI, et al. Acetylcholinesterase activity in CSF in schizophrenia, depression, Alzheimer's disease and normals. Biol Psychiatry 1983; 18: 1353-1373.

13. Lal S, Wood PL, Kiely ME, et al. CSF acetylcholinesterase in dementia and in sequential samples of lumbar CSF. Neurobiol Aging 1984; 5: 269-274.

14. Marquis JK, Volicer L, Mark KA, et al. Cholinesterase activity in plasma, erythrocytes and cerebrospinal fluid of patients with dementia of the Alzheimer type. Biol Psychiatry 1985; 20: 605610.

15. Huff FJ, Maire J-C, Growdon JH, et al. Cholinesterases in cerebrospinal fluid: Correlations with clinical measures in Alzheimer's disease. J Neurol Sci 1986; 72: 121-129.

16. Ruberg M, Villageois A, Bonnet A-M, et al. Acetylcholinesterase and butyrylcholinesterase activity in the cerebrospinal fluid of patients with neurodegenerative diseases involving cholinergic systems. J Neurol Neurosurg Psychiatry 1987; 50: 538-543.

17. Elble R, Giacobini E, Scarsella GF, Cholinesterases in cerebrospinal fluid: A longitudinal study in Alzheimer disease. Arch Neurol 1987; 44: 403-407.

18. Appleyard ME, Smith AD, Berman P, et al. Cholinesterase activities in cerebrospinal fluid of patients with senile dementia of Alzheimer type. Brain 1987; 110: 1309-1322.

19. Augustinsson K-B, Bantai T, Mannervik B. A steady-state kinetic model of butyrylcholinesterase from horse plasma. Biochem $\mathrm{J}$ 1974; 141: 825-834.

20. McKhann G, Drachman D, Folstein M, et al. Clinical diagnosis of Alzheimer's disease: Report of the NINCDS-ADRDA Work Group under the auspices of Department of Health and Human Services Task Force on Alzheimer's disease. Neurology 1984; 34: 939-944.

21. Hachinski VC, Iliff LD, Zilhka E, et al. Cerebral blood flow in dementia. Arch Neurol 1975; 32: 632-637.

22. Mattis $S$. Mental status examination for organic mental syndrome in the elderly patient. In: Geriatric Psychiatry. Edited by $\mathrm{R}$. Bellack and B. Karasu. New York: Grune and Stratton 1976; 77. 121.

23. Vitaliano PP, Breen AR, Russo J, et al. The clinical utility of the Dementia Rating Scale for assessing Alzheimer patients. J Chronic Dis 1984; 37: 743-753.

24. Steele MW, Wenger SL, Chorazy A, et al. Chromosome site of 4q21 and Huntington-like disease. Am J Hum Genet 1987; 41: A85.

25. Johnson CD, Russell RL. A rapid, simple radiometric assay for cholinesterase, suitable for multiple determinations. Anal Biochem 1975; 64: 229-238.

26. Huff FJ, Reiter CT, Rand JB. The ratio of acetylcholinesterase to butyrylcholinesterase influences the specificity of assays for each enzyme in human brain. J Neural Transm 1989; 75: 129134.

27. Bisso GM, Masullo C, Michalek H, et al. Molecular forms of cholinesterases in CSF of Alzheimer's disease/senile dementia of Alzheimer type patients and matched neurological controls. Life Sci 1986; 38: 561-567.

28. Perry EK, Perry RH, Brain biochemistry in dementia of Alzheimertype. In: Metabolic Disorders of the Nervous System. Edited by F.C. Rose. London: Pitman 1981; 382-417. 